\title{
ASPECTOS SENSORIAIS E NUTRICIONAIS DA CERVEJA - COMPARAÇÃO ENTRE O PROCESSO ARTESANAL E COMERCIAL
}

\section{ARTIGO DE REVISÃO}

SILVA, Cláudia Regina Gonçalves da ${ }^{1}$

MORALES, Eduardo Marin ${ }^{2}$

OLIVEIRA, Daniela Soares de ${ }^{3}$

SILVA, Cláudia Regina Gonçalves da. MORALES, Eduardo Marin. OLIVEIRA, Daniela Soares de. Aspectos sensoriais e nutricionais da cerveja - comparação entre o processo artesanal e comercial. Revista Científica Multidisciplinar Núcleo do Conhecimento. Ano 04, Ed. 08, Vol. 01, pp. 14-35. Agosto de 2019. ISSN: 2448-0959, Link de acesso: https://www.nucleodoconhecimento.com.br/nutricao/aspectos$\underline{\text { sensoriais }}$

\section{RESUMO}

Comparar por meio de revisão sistemática, o processo de fabricação das cervejas artesanais e comerciais, em relação aos aspectos nutricionais e sensoriais, além de revisar a legislação brasileira sobre as normas de fabricação das cervejas e analisar as diferenças nos teores alcoólicos entre as cervejas artesanais e comerciais. Foi feita uma comparação entre quatro estudos originais com as seguintes variáveis: diferenças na composição dos ingredientes das fórmulas de cervejas, testes aplicados (como de análise sensorial) e resultados obtidos. O estudo concluiu que cervejas comuns têm menores valores energéticos em relação às cervejas fortes e as extras.

\footnotetext{
${ }^{1}$ Graduanda do Curso de Nutrição.

${ }^{2}$ Doutor em Microbiologia Aplicada; Mestre em Microbiologia Aplicada; Graduado em Engenharia de Alimentos.

${ }^{3}$ Mestrado em Hospitalidade, Graduada em Nutrição.
} 
O mel em sua formulação aumentou os valores energéticos nas cervejas comuns e extras e diminuiu nas fortes. Um estudo mostrou resultados positivos de aceitação da cerveja produzida com mel em relação a formulação padrão, um estudo teve menor aceitação pelas cervejas artesanais de alto e médio teor alcoólico em relação a artesanal industrializada. Um estudo mostrou que $95,6 \%$ das cervejas analisadas utilizavam malte e adjunto cervejeiro e 67,7\% apresentaram quantidades de malte dentro do limite permitido por lei. Os estudos mostraram que a cerveja que tem o mel como adjunto possui alto teor alcoólico em relação as cervejas industriais, além de serem de boa aceitação. A principal diferença entre as cervejas artesanais e comerciais está no processo de fabricação e nos ingredientes utilizados em ambas. A legislação brasileira é um aliado das micro cervejarias e indústrias.

Palavras-chave: cerveja, modalidades sensoriais, legislação, ciências nutricionais.

\section{INTRODUÇÃO}

A legislação brasileira define cerveja como "bebida obtida pela fermentação alcoólica do mosto cervejeiro oriundo do malte de cevada e água potável, por ação da levedura, com adição de lúpulo"1. Chegou ao Brasil durante colonização holandesa, pela Companhia das Índias Ocidentais que, no século XVII, responsável por trazer a cerveja para as terras tupiniquins. Contudo, os holandeses foram expulsos em 1654 e, com isso, a cerveja deixou o Brasil por mais de um século e meio. Seu retorno ocorreu, apenas, no fim do século XVIII e início do XIX uma vez que os portos brasileiros haviam sido fechados para navios estrangeiros, pois os portugueses temiam perder o mercado de vinhos para a cerveja².

Com a chegada da família real portuguesa ao Brasil, os portos foram abertos para nações amigas em 1814, promovendo, assim, o retorno da cerveja, facilitado pelo fato curioso de Dom João VI ser um grande apreciador de cerveja ${ }^{3}$.

As primeiras cervejarias brasileiras surgiram na década de 1870 e 1880, sendo a Friederich Christoffel (Porto Alegre - RS) a pioneira que, somente em 1878, produziu mais de um milhão de garrafas. No entanto, somente em 1880 instalaram-se no Rio 
de Janeiro as primeiras máquinas compressoras frigoríficas, possibilitando, assim, a produção de cervejas de baixa fermentação, com característica uniforme e límpida, como as da Bavária $\AA^{\circledR}$ e Boêmia ${ }^{\circledR}$, que mais tarde dominariam o mercado nacional ${ }^{4}$.

A cerveja mais consumida no Brasil é a Pilsen, fabricada em grandes lotes e por grandes indústrias. No entanto, os consumidores brasileiros têm apresentado um interesse, cada dia mais presente no mercado brasileiro, por cervejas artesanais, fabricadas em micro cervejarias. Normalmente essas cervejas apresentam aspectos físico-químicos mais interessantes como corpo, muitas vezes acrescidas de frutas, tornando-as com um sabor e aroma peculiares, ideais para um público mais seletivo ${ }^{5}$.

As cervejas consideradas como uma das bebidas alcoólicas de menor teor de etanol. Um litro de cerveja equivale: em carboidratos, a $150 \mathrm{~g}$ de pão; em proteínas, a $60 \mathrm{~g}$ de pão, $120 \mathrm{~g}$ de leite ou ainda $25 \mathrm{~g}$ de carne ${ }^{6}$.

As cervejas são classificadas quanto ao extrato primitivo, ou seja, quanto ao extrato do mosto de malte de origem da cerveja, sendo classificada como: a) cerveja leve, com extrato primitivo entre $5 \%$ e $10,5 \%$ em peso; b) cerveja ou cerveja comum, com extrato primitivo maior ou igual a 10,5\% em peso e menor que $12 \%$ em peso; c) cerveja extra, com extrato primitivo maior ou igual a $14 \%$ em peso; d) cerveja forte, com extrato primitivo maior que $14 \%$ em peso 1 .

De acordo com Rebello (2009) ${ }^{7}$ para a fabricação da cerveja são utilizados os ingredientes abaixo, com as seguintes recomendações:

Ingredientes utilizados na fabricação da cerveja

Água Deve ser inócua, livre de contaminações e dura (alto teor de cálcio e magnésio) para servir de nutriente para as leveduras fermentativas. Também deve ser clorada, sem presença de ferro, $\mathrm{pH}$ deve ser ajustado para 5,0.

Malte de cevada Oriundo da cevada germinada e seca ( $4 \%$ de umidade), rico em açúcar e enzimas, moído com granulometria controlada macerada por doze horas. 


\begin{tabular}{|c|c|}
\hline Gritz de milho & $\begin{array}{l}\text { Corresponde de } 30 \text { a } 40 \% \text { em peso de carboidratos presentes } \\
\text { nas cervejas comerciais. }\end{array}$ \\
\hline Açúcares & Adicionado através de sacarose, ou xarope de açúcar invertido. \\
\hline $\begin{array}{l}\text { Cereais não } \\
\text { maltados }\end{array}$ & Conferem à cerveja menos cor e características específicas \\
\hline Lúpulo & $\begin{array}{l}\text { É o mais importante conservante da cerveja. Utiliza-se a flor } \\
\text { feminina desidratada do lúpulo, que tem características que } \\
\text { garantem amargor e aroma na cerveja, sendo possível o uso do } \\
\text { extrato de lúpulo. É o último ingrediente a ser dosado. Contribui } \\
\text { para a formação de espumas e protege a cerveja contra } \\
\text { contaminações microbiológicas. }\end{array}$ \\
\hline Aditivos & $\begin{array}{l}\text { Os mais utilizados são, corante caramelo, estabilizante de } \\
\text { espuma, estabilizante coloidal e antioxidante. }\end{array}$ \\
\hline $\begin{array}{l}\text { Coadjuvantes } \\
\text { tecnológicos }\end{array}$ & Floculador de proteína e terra filtrante. \\
\hline $\begin{array}{l}\text { Levedura } \\
\text { cervejeira }\end{array}$ & $\begin{array}{l}\text { O agente promotor da fermentação é a levedura Sacharomyces } \\
\text { cerevisae, que se reproduz por gemulação (brotamento). } \\
\text { Existem dois principais tipos de fermentação, sendo: de alta } \\
\text { fermentação (também conhecida por Ale) e de baixa } \\
\text { fermentação (também conhecida por Lager), porém no Brasil a } \\
\text { mais utilizada pelas indústrias são as de baixa fermentação. }\end{array}$ \\
\hline
\end{tabular}

Fonte: Rebello,20097.

O processamento da cerveja baseia-se basicamente em quatro etapas: 1. Malteação (consiste na germinação da cevada e é realizada em maltarias, fora das cervejarias); 2. Produção do mosto cervejeiro (extração e hidrólise dos componentes da cevada malteada, também conhecida por sacarificação, separação dos componentes insolúveis, também conhecido por "trub" e fervura, na qual ocorre a adição do lúpulo); 3. Fermentação: conversão dos açúcares em álcool (derivado do metabolismo anaeróbio das leveduras); 4. Maturação: etapa em que ocorrem reações químicas 
(esterificação) que melhoram as características da cerveja; e 5. Processamento final: filtração, estabilização e engarrafamento ${ }^{8}$.

A cerveja artesanal, fabricada em micro cervejarias, é caracterizada por uma cerveja mais encorpada, com maior teor de carboidratos derivados do malte. A principal diferença entre a cerveja elaborada por micro cervejarias e grandes cervejarias é explicada pela utilização de maiores quantidades de malte e de lúpulo

Pode-se dizer que não há muita diferença das micro cervejarias com as indústrias de grande porte com relação aos equipamentos e processos de fabricação, a menos que estas não necessitem de filtração e envasamento. Sendo assim, a instalação de micro cervejarias é muito mais simples, podendo ser observado processos manuais na fabricação das cervejas ${ }^{10}$.

Falando-se na evolução do consumo de álcool no Brasil, principalmente com relação à cerveja, pesquisas mostram que ocorre um crescimento significativo desde a segunda metade de 1980. Propagandas promovem um estímulo precoce ao consumo entre os jovens, fazendo com que seja consumido antes da idade legal permitida ${ }^{11}$.

De acordo com alguns estudos existe uma relação entre o consumo de álcool, incluindo a cerveja, e o sobrepeso devido ao seu alto teor calórico ${ }^{12}$.

Segundo Ferreira (2008) $)^{10}$ a quantidade total de álcool consumido, (particularmente relacionado ao consumo da cerveja), exerce grande influência sobre a adiposidade abdominal que pode levar a diversos problemas de saúde.

O excesso de gordura corporal pode fazer com que ocorra o aparecimento de diversas disfunções metabólicas e funcionais, podendo desenvolver diabetes, disfunções pulmonares, doenças cardiovasculares, problemas biliares, câncer, dislipidemias, hipertensão arterial, osteoartrite e resistência à insulina ${ }^{13 .}$

O consumo moderado e usual de álcool, além de uma fonte de energia adicional, é considerado como "caloria vazia", pois, apesar de apresentar alto valor energético, faltam nutrientes, vitaminas, minerais e elementos traços ${ }^{14}$. 
Estudos sugerem que a ingestão leve a moderada de álcool, pode reduzir a morbidade e a mortalidade. Outro ponto é que os consumidores de vinho, se comparados com os consumidores de cerveja e destilados possuem menor risco de morte por diversas as causas. Isto pode estar relacionado ao fato de que a cerveja contém nitrosaminas possivelmente carcinogênicas, podendo até desenvolver cirrose alcoólica ${ }^{15}$.

O Ministério da Agricultura, Pecuária e Abastecimento (MAPA) é o órgão responsável pela regulamentação do setor cervejeiro brasileiro. As empresas devem atender uma série de características físico-químicas (teor alcoólico, cor, teor de extrato) e sensoriais (sabor e aroma). Também devem cumprir os conceitos de Boas Práticas de Fabricação (BPF), assegurando que o produto final será de qualidade ${ }^{1}$.

O MAPA apresenta a seguinte legislação vigente:

- Lei 8.918/1994 - Dispõe sobre a padronização, a classificação, o registro, a inspeção, a produção e a fiscalização de bebidas, autoriza a criação da Comissão Internacional de Bebidas e dá outras providências.

- Decreto 6.871/2009 - Regulamenta a Lei no 8.918, de 14 de julho de 1994, que dispõe sobre a padronização, a classificação, o registro, a inspeção, a produção e a fiscalização de bebidas.

- Instrução Normativa 05/2000 - Aprova o regulamento Técnico para a fabricação de bebidas e vinagres, inclusive vinhos e derivados da uva e do vinho, dirigido a estabelecimentos elaboradores e/ou industrializadores, conforme consta do Anexo desta Instrução Normativa.

- Instrução Normativa 54/2001 - Adota o Regulamento Técnico MERCOSUL de produtos de cervejarias, em conformidade ao disposto no Anexo da presente Instrução Normativa ${ }^{1}$.

Importante ressaltar que o MAPA possui um serviço de inspeção, chamado de SIPOV (Serviço de Inspeção de Produtos de Origem Vegetal) que é responsável pelo registro e fiscalização de bebidas em todas as Superintendências Federais de agricultura nas unidades de federação, deve-se contatar o serviço que corresponde ao Estado de localização da cervejaria para as demais resoluções pontuais. A cervejaria deve ter 
um registro no MAPA para funcionar, e isso não a isenta das demais licenças para o funcionamento ${ }^{1}$.

O objetivo desse estudo foi comparar as cervejas artesanais e comerciais em relação aos aspectos nutricionais e sua legislação; bem como revisar a legislação brasileira sobre as normas de fabricação das cervejas e analisar as diferenças nos teores alcoólicos entre as cervejas artesanais e comerciais.

\section{MÉTODOS}

Foi realizada uma busca em revistas cientificas, que analisaram os aspectos nutricionais das cervejas artesanais e comerciais. A pesquisa foi realizada em base de dados online como Pubmed, Scielo e Lilacs e em sites como Bireme, utilizando as palavras-chave "cerveja", "cerveja artesanal", "cerveja comercial", "aspectos nutricionais", "fabricação de cervejas", "tipos de cerveja", "legislação" e seus respectivos em inglês; sendo analisados artigos em inglês e português do ano de 2000 a 2018.

Como critérios de inclusão foram utilizados artigos originais e de revisões que descrevessem os aspectos nutricionais da cerveja artesanal e comercial, da legislação que rege o mercado cervejeiro no Brasil, além de artigos que descrevessem os tipos de cervejas existentes em todo país.

Os critérios de exclusão foram: artigos que abordassem somente o mercado internacional ou somente a fabricação das cervejas com foco em Tecnologia dos Alimentos ou Microbiologia.

Para comparar os estudos foram utilizados: diferenças nos componentes nutricionais das fórmulas de cervejas, teor alcoólico, testes aplicados (como de análise sensorial, por exemplo) e resultados obtidos.

A estratégia de pesquisa encontrou 30 artigos. Foram selecionados 4 artigos que correlacionavam as cervejas artesanais e comerciais em relação aos aspectos nutricionais, legislação e diferença nos teores alcoólicos. 


\section{RESULTADOS}

Brunelli e Venturini Filho ${ }^{16}$, relataram um estudo que teve como objetivo caracterizar energeticamente cervejas elaboradas com mel, sendo analisadas três concentrações de extrato primitivo (Brix ${ }^{[4]} 11,13,1^{\circ}$ ) e três porcentagens de mel na formulação do mosto cervejeiro (0, 20 e 40\%). Na formulação de extrato primitivo $11^{\circ}$ Brix (cerveja comum), com a proporção $0 \%$ de mel, houve $3,18 \mathrm{~g}$ de álcool, com $20 \%$ de mel, esse valor chegou em $3,36 \mathrm{~g}$ e com $40 \%$ de mel o valor encontrado foi de $3,84 \mathrm{~g}$ de álcool, com carboidrato de $1,29 \mathrm{~g}, 1,12 \mathrm{~g}, 0,64 \mathrm{~g}$ respectivamente. Na formulação de extrato primitivo $13^{\circ}$ Brix (cerveja extra) os resultados encontrados foram em $0 \%$ de mel $3,78 \mathrm{~g}$ de álcool, com $20 \%$ de mel, $4,50 \mathrm{~g}$ de álcool e com $40 \%$ de mel, o valor encontrado foi de 4,63g de álcool, tendo o carboidrato os valores de 1,48g, 0,96g e 0,92g respectivamente. $\mathrm{Na}$ formulação com extrato primitivo $15^{\circ}$ Brix (cerveja forte), os resultados obtidos foram, com $0 \%$ de mel, $4,33 \mathrm{~g}$ de álcool, com $20 \%$ de mel, $4,37 \mathrm{~g}$ de álcool e com $40 \%$ de mel $4,72 \mathrm{~g}$ de álcool, sendo que o carboidrato atingiu os valores de $1,44 \mathrm{~g}, 1,17 \mathrm{~g}$ e $0,81 \mathrm{~g}$, respectivamente.

As cervejas elaboradas sem mel apresentaram maiores teores médios de carboidratos, devido a presença da dextrina, um carboidrato não fermentescível nos mostos da cerveja puro malte. Em relação aos teores alcoólicos, as cervejas que foram elaboradas com menor teor de extrato primitivo (11 ${ }^{\circ}$ Brix) apresentaram menores valores, devido aos açúcares presentes serem de menor concentração, enquanto que a cerveja produzida com $40 \%$ de mel apresentou teores alcoólicos elevados em relação as cervejas preparadas sem mel ${ }^{16}$.

Estudo realizado por Oliveira et el. ${ }^{17}$, tinha como objetivo elaborar cerveja artesanal utilizando o mel como substituinte parcial do malte e como aromatizante natural de cervejas artesanais. Foram utilizadas quatro formulações diferentes de cerveja, sendo uma fórmula puro malte e as outras com 10, 20 e 30\% de substituição do malte por mel. Obteve-se os seguintes resultados, a amostra 01 (puro malte) apresentou um teor alcoólico de 4,9\%v, já a amostra 02 (com 10\% de substituição do malte por mel) apresentou $5,2 \% \mathrm{v}$, a amostra 03 (20\% de substituição do malte por mel) apresentou $5,8 \%$ v e a amostra 04 (com 30\% de substituição do malte por mel) o teor alcoólico 
ficou em $5,6 \%$ v. Os testes sensoriais mostraram que as cervejas que tiveram o malte substituído parcialmente por mel foram de boa aceitação do público.

Silva et al ${ }^{18}$, realizaram um estudo sobre a elaboração de cerveja com diferentes teores alcoólicos médio e alto, através do processo artesanal. Foram analisadas três amostras de cerveja de alto e médio teor alcoólico produzidas artesanalmente e uma amostra de cerveja industrializada. $\mathrm{Na}$ análise encontrou-se na cerveja de alto teor alcoólico uma concentração de $5,2 \pm 0,2 \% \mathrm{v} / \mathrm{v}$ e na cerveja com médio teor alcoólico uma concentração der $4,4 \pm 0,2 \% \mathrm{v} / \mathrm{v}$, sendo que a amostra artesanal industrializada, no rótulo indicava $4,7 \% \mathrm{v} / \mathrm{v}$, sendo considerada de alto teor alcoólico. Foi realizado um teste de aceitabilidade com 60 avaliadores não treinados. A análise sensorial mostrou que as cervejas artesanais de alto e médio teor alcoólico são de menor aceitação em relação a industrializada.

Sleiman et al. ${ }^{19}$ elaboraram um estudo sobre a determinação do percentual de malte e adjuntos em cervejas comerciais brasileiras através de análise isotópica. Esse estudo teve como objetivo determinar a quantidade de malte e de adjunto presentes nas cervejas brasileiras do tipo Pilsen, tendo como base a legislação brasileira. Utilizou-se uma amostra com 161 cervejas de dezessete estados do Brasil. Concluiuse que $95,6 \%$ das amostras utilizaram em sua formulação malte e adjunto cervejeiro, sendo $91,3 \%$ derivados de milho ou açúcar de cana e 4,3\% derivados de arroz, porém $4,3 \%$ eram cervejas puro malte. Do total estudado, $3,7 \%$ eram cervejas adulteradas, consideradas ilegais perante a legislação brasileira, 28,6\% estavam na incerteza em relação ao percentual de malte, independentemente do adjunto utilizado e os outros $67,7 \%$ estavam com as quantidades de maltes dentro do limite estabelecido pela legislação brasileira.

Nos estudos selecionados, os resultados encontrados foram alto teor alcoólico, que ficou na faixa de $4,4 \% \mathrm{v} / \mathrm{v}$ a $5,8 \% \mathrm{v} / \mathrm{v}$ de álcool. Foram aplicados teste de aceitabilidade em 2 estudos, sendo que 1 estudo a cerveja elaborada com mel foi de boa aceitação e, no outro, não houve boa aceitação. Dois estudos não fizeram o teste aceitabilidade, somente compararam os ingredientes utilizados, inclusive os adjuntos, como o mel. A substituição parcial do malte por mel pode ainda favorecer o processo de fabricação 
da cerveja sem prejudicar suas características organolépticas, além de se tornarem mais atrativas.

A tabela abaixo mostra os resultados obtidos com informações relevantes.

\begin{tabular}{|c|c|c|c|c|c|c|}
\hline Autor & Malte & Lúpulo & Adjuntos & Teor alcoólico & Análise sensorial & Resultados \\
\hline \multirow[t]{2}{*}{$\begin{array}{l}\text { Oliveira, et } \\
\text { al. (2015) }\end{array}$} & $\begin{array}{c}4 \text { kg e } 12 \\
\text { kg de } \\
\text { água } \\
\text { (proporção } \\
1 \text { para } 3\end{array}$ & $\begin{array}{l}\text { Utilizado } \\
\text { pélletes } \\
\text { (método } \\
\text { das três } \\
\text { cargas) }\end{array}$ & Mel & $\begin{array}{c}11^{\circ} \text { Brix - 3,18g } \\
13^{\circ} \text { Brix - 3,78g } \\
15^{\circ} \text { Brix - 4,33g } \\
\text { Com } 20 \% \text { de mel: } \\
11^{\circ} \text { Brix - 3,36g } \\
13^{\circ} \text { Brix - 4,50g } \\
15^{\circ} \text { Brix - 4,37g } \\
\text { Com 40\% de mel: } \\
11^{\circ} \text { Brix - 3,84g } \\
13^{\circ} \text { Brix - 4,63g } \\
15^{\circ} \text { Brix - 4,72g }\end{array}$ & $N / R$ & $\begin{array}{c}\text { Cervejas comuns } \\
\text { mostraram menores } \\
\text { valores energéticos } \\
\text { em relação às } \\
\text { cervejas fortes e as } \\
\text { extras. A presença } \\
\text { do mel em sua } \\
\text { formulação } \\
\text { aumentou os } \\
\text { valores energéticos } \\
\text { nas cervejas } \\
\text { comuns e extras e } \\
\text { diminuiu nas fortes. }\end{array}$ \\
\hline & $\begin{array}{c}6 \text { kg em } \\
\text { grão seco }\end{array}$ & $\begin{array}{c}\text { Aromático: } \\
6 \mathrm{~g} \text { Saaz } \\
\text { pellet 2,5\% } \\
\text { alfa ácido }\end{array}$ & Mel & $\begin{array}{l}100 \% \text { malte: } 4,9 \% \mathrm{v} \\
10 \% \text { de mel: } 5,2 \% \mathrm{v} \\
20 \% \text { de mel: } 5,8 \% \mathrm{v} \\
30 \% \text { de mel: } 5,6 \% \mathrm{v}\end{array}$ & $\begin{array}{c}\text { Testes de } \\
\text { ordenação(cor, } \\
\text { sabor e aspecto } \\
\text { global), não }\end{array}$ & $\begin{array}{c}\text { Boa aceitação, } \\
\text { não houve } \\
\text { diferença } \\
\text { significativa de }\end{array}$ \\
\hline
\end{tabular}

\begin{tabular}{|c|c|c|c|c|c|c|}
\hline & & $\begin{array}{l}\text { Amargor: } \\
5 \mathrm{~g} \text { Gallena } \\
\text { pellet } \\
12,5 \% \text { alfa } \\
\text { ácidos }\end{array}$ & & & $\begin{array}{c}\text { apontou diferença } \\
\text { significativa entre } \\
\text { as cervejas } \\
\text { elaboradas. }\end{array}$ & $\begin{array}{c}\text { preferência } \\
\text { entre as } \\
\text { formulações } \\
\text { contendo mel e } \\
\text { a formulação } \\
\text { padrão }\end{array}$ \\
\hline $\begin{array}{l}\text { Silva, et.al } \\
\text { (2009) }\end{array}$ & $\begin{array}{l}\text { Médio teor } \\
3.0 \mathrm{~kg} \\
\text { Alto teor } \\
3,5 \mathrm{~kg}\end{array}$ & $\begin{array}{c}\text { Aromático: } \\
\text { Médio teor: } \\
7,5 \mathrm{~kg} \\
\text { Alto teor: } 7,5 \\
\mathrm{~kg} \\
\text { Amargor } \\
\text { Médio teor: } \\
7,5 \mathrm{~kg} \\
\text { Alto teor: } \\
7,5 \mathrm{~kg}\end{array}$ & $\mathrm{~N} / \mathrm{A}$ & $\begin{array}{c}\text { Médio teor alcoólico: } \\
4,4 \pm 0,2 \% \mathrm{v} / \mathrm{v} \\
\text { Alto teor alcoólico: } \\
5,2 \pm 0,2 \% \mathrm{v} / \mathrm{v} \\
\text { Artesanal } \\
\text { industrializada (alto } \\
\text { teor alcoólico): } \\
4,7 \% \mathrm{v} / \mathrm{v}\end{array}$ & $\begin{array}{c}\text { Teste de } \\
\text { aceitabilidade } \\
\text { realizados com } 60 \\
\text { avaliadores não } \\
\text { treinados }\end{array}$ & $\begin{array}{c}\text { Menor } \\
\text { aceitação pelas } \\
\text { cervejas } \\
\text { artesanais de } \\
\text { alto e médio } \\
\text { teor alcoólico } \\
\text { em relação a } \\
\text { industrializada }\end{array}$ \\
\hline
\end{tabular}




\begin{tabular}{cccc}
\hline 67\% das & N/A & $91,3 \%$ & N/A \\
cervejas & milho ou & & N/R \\
analisadas & açúcar de & & $95,6 \%$ das \\
estavam & cana & cervejas \\
de acordo & $4,3 \%$ & analisadas \\
com a lei & derivados & utilizavam \\
$(161$ & de arroz & malte e adjunto & cervejeiro. \\
amostras $)$ & $4,3 \%$ puro & $67,7 \%$ \\
& malte & apresentaram \\
& & quantidades de \\
& & malte dentro do \\
& & limite permitido \\
& & por lei.
\end{tabular}

Fonte: Próprio autor

$N / A=$ não analisado $/ N / R=$ não realizado

\section{DISCUSSÃO}

\section{ASPECTOS DO PROCESSO CERVEJEIRO}

No processo cervejeiro, o principal fornecedor dos açúcares é o malte. Ingrediente fundamental para o processo fermentativo. É a concentração destes açúcares que possibilita a ação das leveduras, proporcionando características sensoriais e físicoquímicas específicas da cerveja durante a fermentação e maturação ${ }^{5}$. Desta maneira, durante o processo de fabricação da cerveja, maior ou menor quantidade de açúcares disponíveis para o processo fermentativo derivam da quantidade de malte de cevada utilizado. Ou seja, quanto maior a quantidade de malte mais açúcares disponíveis e, consequentemente, maior o teor alcoólico da cerveja. Sendo assim, a variação no uso da quantidade de malte, bem como suas variedades, caracteriza não somente a graduação alcoólica, mas também características sensoriais da cerveja 20.

Como dito anteriormente, esses açúcares estão relacionados ao processo fermentativo da cerveja que, conforme metabolizados pela levedura são transformados em álcool etílico e $\mathrm{CO}_{2}{ }^{21}$. Desta maneira, quanto maior a concentração de açúcares fermentáveis, maior será a graduação alcoólica da cerveja ${ }^{22}$. No entanto, o processo de sacarificação da cerveja não produz apenas açúcares fermentáveis, 
mas também uma pequena concentração de dextrinas (não fermentáveis) que estão relacionados ao corpo da cerveja ${ }^{16,22}$.

No estudo realizado por Sleiman et al. $(2010)^{19}$, mais de 160 amostras de cerveja de todas as regiões brasileiras foram analisadas quanto à presença malte na composição mediante a avaliação do $\delta{ }^{13} \mathrm{C}$, que se trata de um método de análise isotópica. Neste estudo, os autores observaram que $91,4 \%$ das cervejas brasileiras utilizam adjuntos provenientes do milho e da cana-de-açúcar, sendo que algumas delas (3,1\% do total) apresentavam-se fora dos padrões exigidos pela legislação vigente. Outro dado importante da pesquisa foi que apenas $4,3 \%$ das amostras analisadas poderiam ser consideradas "puro malte", sendo que as demais apresentavam algum adjunto na composição.

Outros diversos compostos derivam das matérias-primas da cerveja e contribuem para o aroma, sabor e cor da cerveja. Para que possam ser considerados como aspectos positivos, essas matérias-primas devem ser utilizadas de maneira equilibrada, uma vez que o excesso ou a deficiências desses compostos pode determinar a aceitação ou a rejeição pelos consumidores ${ }^{23}$. A cor da cerveja está diretamente relacionada à presença de açúcares caramelizados derivados dos diferentes processos de torrefação de matérias-primas, principalmente o malte ${ }^{22,24}$. Em vários países é permitida a substituição do malte por adjuntos, pois podem apresentar menores custos de produção.

Silva et $a l^{18}$, mostrou em seu estudo que houve menor aceitação pelas cervejas artesanais de alto e médio teor alcoólico do que as industrializadas. Enquanto que no estudo de Oliveira et al ${ }^{17}$, as cervejas artesanais foram bem aceitas, mas não houve diferença significativa na aceitação entre a cerveja acrescida de mel e a de formulação padrão.

\section{ASPECTOS SENSORIAIS}

A cerveja é uma das bebidas mais delicadas e, apesar da complexidade de suas características, deve apresentar sabor e aroma moderados e equilibrados. Esse 
equilíbrio está relacionado aos compostos voláteis e não voláteis presentes que são os principais responsáveis pela aceitação ou rejeição e, consequentemente, pela qualidade da bebida ${ }^{5}$. Apresenta características levemente ácidas derivadas do malte de cevada utilizado e dos ácidos orgânicos produzidos pelas leveduras durante o processo fermentativo, sendo que a faixa de acidez correta é fundamental para a sensação agradável ao paladar humano 22 .

Durante a fase de fermentação da cerveja, a assimilação de compostos nitrogenados pelas leveduras promove o aparecimento de álcoois superiores que participam, quando em baixas concentrações, da qualidade aromática da cerveja. Contudo, quando ocorrem em altas concentrações podem afetar a qualidade da espuma, defeitos sensoriais e, em casos extremos, dores de cabeça. A produção de ácidos superiores está relacionada, principalmente, a problemas no controle da temperatura de fermentação, sendo que temperaturas mais elevadas durante esse período podem levar à produção mais intensa desses álcoois 7,22,25.

Com relação aos atributos sensoriais das cervejas, foi realizado um estudo com avaliadores treinados para diferenciação entre cervejas artesanais e líderes de mercado (comerciais). Neste estudo, observou-se que a cor, o aroma de leveduras, sabor mais adocicado e o gosto amargo foram mais acentuados em cervejas artesanais ${ }^{5}$. Essas observações mostram que o uso de maiores quantidades de malte influencia na cor, principalmente pelo uso de diferentes tipos de maltes de cevada (maltes base, caramelizados, torrados, etc.), fator este que pode influenciar tanto positiva quanto negativamente na escolha pelo consumidor.

Quanto ao atributo "cor", o estudo de Araújo et al. (2003) $)^{5}$ mostrou que as cervejas comerciais apresentam coloração muito mais clara e pode estar relacionada ao fato do uso de menores variedades de malte (principalmente maltes base, que não agregam cores mais intensas) e o maior uso de adjuntos, como os xaropes de açúcares que, normalmente, não possuem cor. O dulçor, detectado mais intensamente nas cervejas artesanais também está relacionado ao fato do maior uso de malte na formulação, sendo que, durante o processo de sacarificação (preparo do mosto para a fermentação) ocorre a conversão do amido presente nos grãos de malte 
de cevada em açúcares fermentáveis e não fermentáveis. Esses açúcares não fermentáveis, como não são metabolizados pelas leveduras, permanecem após o processo de fermentação, gerando o dulçor mais elevado. O amargor mais acentuado detectado no mesmo experimento está diretamente associado ao maior uso de lúpulo nas formulações de cervejas artesanais, o que garante mais amargor, aroma e estabilidade microbiológica. Um fato importante observado pelos autores da pesquisa acima mencionada (Araújo, et al. 2003) ${ }^{5}$, foi a evidência de que as cervejas artesanais apresentaram atributos sensoriais mais intensos, caracterizada pelo maior uso de diferentes tipos de malte e lúpulos.

Apesar das variedades diversas de cervejas disponíveis para o consumidor e seus diferentes atributos e apelos comerciais, cabe evidenciar que são fontes de folatos, vitaminas do complexo $B$ (niacina, piridoxina e cianocobalamina), além de fontes de selênio. Também apresentam efeito diurético derivado da relação potássio/sódio que ocorre em sua composição 26,27 .

Outra característica importante de suas matérias-primas é a propriedade antibiótica e anti-inflamatória do lúpulo, que também apresenta efeitos bioativos. As propriedades antioxidantes dos ácidos fenólicos colaboram com a prevenção do câncer devido a sua capacidade de "sequestrar" radicais livres ${ }^{28,29}$. No entanto, o consumo moderado de álcool pode estar relacionado aos efeitos observados anteriormente, o que não ocorre no consumo excessivo do mesmo ${ }^{26}$.

Atualmente, tem ocorrido o aumento do interesse de compostos fenólicos em alimentos e bebidas ${ }^{30}$. Apesar dos polifenóis estarem principalmente relacionados ao consumo de frutas, vinho, chá, café e chocolate, a cerveja pode ser considerada uma boa fonte desse composto, apresentando quantidades consideráveis de polifenóis derivados do malte e do lúpulo ${ }^{30,31}$. Na cerveja, cerca de $70-80 \%$ dos compostos fenólicos derivam do malte e 20-30\% do lúpulo, contudo, os compostos fenólicos provenientes do malte sofrem transformações durante o processamento e, por esse motivo, não são tão bem caracterizados como os derivados do lúpulo ${ }^{32}$. 
A cerveja também pode ser considerada uma ótima fonte de água, uma vez que é constituída por 91 a 92\% dessa substância, contudo, apresenta entre 4,5 a 5,5\% (v/v) de álcool (principalmente o álcool etílico e em menor quantidade os álcoois superiores), que é absorvido diretamente pelo organismo e convertido em energia. $\mathrm{O}$ extrato da cerveja é composto por cerca de $75-80 \%$ de carboidratos (principalmente dextrinas), minerais, taninos, compostos amargos e ácidos orgânicos. Deste modo, a cerveja apresenta importância nutricional e fisiológica quando comparada com outras bebidas, estimulando o apetite e favorecendo o processo de digestão, uma vez que as enzimas responsáveis pela digestão são estimuladas por baixas concentrações de álcool e $\mathrm{CO}_{2}$. Apesar das leveduras absorverem quase todo o conteúdo de vitamina $B_{1}$, as cervejas ainda contem vitaminas $B_{1}, B_{2}$, sendo que as cervejas não filtradas (principais características das artesanais) oferecem maiores quantidades de vitaminas. Além de todos esses nutrientes, a cerveja ainda apresenta cerca de 4,3\% de seu conteúdo em proteínas ${ }^{33}$. Tais quantidades se tornam mais evidentes em cervejas artesanais, decorrentes do uso de maiores quantidades de malte e lúpulo, caracterizando melhor qualidade nutricional em cervejas artesanais ou "puro malte".

A cerveja, assim como qualquer outra bebida alcoólica, se a ingestão for excessiva pode trazer muitos malefícios a saúde. Segundo Valério et.al $(2016)^{34}$, o consumo de valor igual ou superior a 30 gramas diárias de álcool pode alterar o equilíbrio da homeostase energética e provocar um aumento do apetite, e consequentemente aumentar o ganho de peso. A cerveja apresenta maior associação com a gordura corporal central. O consumo do álcool, inclusive da cerveja e o acréscimo energético proveniente deste, pode colaborar para um eventual ganho de peso, além de causar dependência química, alcoolismo e possível desenvolvimento de doenças relacionadas ao acúmulo da gordura corporal e visceral ${ }^{34}$.

O álcool, inclusive a cerveja, tem prioridade no metabolismo, altera as vias metabólicas, incluindo a oxidação lipídica, favorecendo o estoque de gorduras no organismo. Para cada grama de álcool metabolizada, são formadas $7,1 \mathrm{kcal} / \mathrm{g}$, fazendo que se torne uma fonte energética considerável se comparada aos carboidratos $(4 \mathrm{kcal} / \mathrm{g})$, proteínas $(4 \mathrm{kcal} / \mathrm{g})$ e lipídeos $(9 \mathrm{kcal} / \mathrm{g})^{35}$. 
Além disso, o estudo de Gronbaek et al. (2004) ${ }^{15}$ comparou o risco de desenvolver cirrose hepática entre bebedores de vinho e bebedores de cerveja, constatando que o risco é maior para os bebedores excessivos de cerveja.

\section{CONCLUSÃO}

A bebida mais frequentemente consumida pelo brasileiro é a cerveja, apesar de muitos ainda consumirem outros tipos de bebidas alcoólicas. Vários estudos mostraram que as cervejas podem possuir teores alcoólicos classificados como alto e médio, principalmente quanto adicionado de algum adjunto, como o mel, por exemplo.

Comparando as cervejas artesanais e comerciais, foi possível ver que a principal diferença entre elas está no processo de fabricação e na matéria prima, pois a cerveja industrial usa $60 \%$ de malte e o restante utiliza outros cereais, como o milho e arroz, já a artesanal é fabricada com ingredientes selecionados e o seu processo de fabricação tem um cuidado todo especial, possui um sabor mais acentuado e pode ainda ser acrescida de mel e frutas.

Além disso, estudos mostraram que apesar das cervejas terem componentes nutricionais importantes, como vitaminas, principalmente as artesanais acrescidas de frutas, o consumo está relacionado ao aumento da adiposidade abdominal e do peso, dentre outras patologias, sendo necessário ingerir com moderação.

\section{REFERÊNCIAS}

1. Brasil. Ministério da Agricultura, Pecuária e Abastecimento. Decreto oํ 6871 de 14 de junho de 2009. Padronização, a classificação, o registro, a inspeção, e a fiscalização da produção e do comércio de bebidas. Diário Oficial da União, Poder Executivo, Brasília, DF, 2009.

2. Coelho-Costa E R, A bebida de Ninkasi em terras tupiniquins: O mercado da cerveja e o turismo cervejeiro no Brasil, Rer. Iberoamericana de Turismo.2015; $5(1): 22-41$. 
3. Coutinho, C A T, Cerveja marca barbante ou a história da cerveja no Brasil. Disponível em: http://www.cervisiafilia.com.br/cervbras2.html. Acesso em 30.08.2018.

4. Santos, S P, Os primórdios da cerveja no Brasil, 2ed.Cotia: Ateliê Editorial, 2004.

5. Araújo, F.B.; Silva, P.H.A.; Minim, V. P. R. Perfil sensorial e composição físicoquímica de cervejas provenientes de dois segmentos do mercado brasileiro. Ciência e Tecnologia de Alim. 2003;23(2):121-128.

6. Coimbra, A R, Melo F, Agostinho P, Cerveja e Saúde. Disponível em: http://www.ff.uc.pt/ mccast/nutricao/material/Cerveja_saúde.pdf. Acesso em 02/09/2018.

7. Rebello F F P., Produção de cerveja, Rev. Agrogeoembiental. 2009; 1(3):145155.

8. Linko M, Haikara A, Ritala A, Pwenttilã M, Recent advances in the malting and brewing industry. Journal of Biotechnology, 1998;65(2-3):85-98.

9. Keukeleire D, Fundamentals of beer and hop chemistry, Rev. Química nova. 2000;23(1):108-112.

10. Ferreira, M G., Valente J G., Silva R M V G., Sichieri R., Consumo de bebida alcoólica e adiposidade abdominal em doadores de sangue, Rev. Saúde Pública, 2008;42(6):1067-1073.

11. Pinsky I, Pavarino Filho R V, A apologia do consumo de bebidas alcoólicas e da velocidade no trânsito no Brasil: considerações sobre a propaganda de dois problemas de saúde pública. Ver Psiquiatr RS. 2007;29(1):110-118.

12. Cibeira, G H, Muller C., Lazzaretti R., Nader G A., Caleffi M., Consumo de bebida alcoólica, fatores socioeconômicos e excesso de peso: um estudo transversal no sul do Brasil, Rev. Ciência e Saúde Coletiva.2013;18(12):35773584.

13. Mariath A B, e colaboradores. Obesidade e fatores de risco para o desenvolvimento de doenças crônicas não transmissíveis entre usuários de unidade de alimentação e nutrição. Univ. Vale do Itajaí, 2007.

14. Meloni J N, Laranjeira R, Custo social e de saúde do consumo de álcool. Unid. de Pesq. em álcool e drogas. Vinhedo, 2004. 
15. Gronbaek M., Jenses M K., Johansen D., Sorensen T I., Becker U., Intake of beer, wine and spirits and risk of heavy drinking and alcoholic cirrhosis, Biol. Res. 2004; 37:195-200.

16. Brunelli, L.T.; Venturini Filho W. G. Análise energética de cerveja elaborada com mel. Rev. Energia na Agric.2013;28(2):122-128.

17. Oliveira, M., Faber C R., Plata-Oviedo M S V., Elaboração de cerveja artesanal a partir da substituição parcial do malte por mel, REBRAPA Brazilian Journal of Food Research. 2015;6(3):01-10.

18. Silva, A E, Colpo E, Oliveira V R, Herbst Junior C G, Hecktheuer L H R, Reichert F S, Elaboração de cerveja com diferentes teores alcoólicos através de processo artesanal, Alim. Nutr.2009;20(3):369-374.

19. Sleiman M. Venturini Filho W G, Ducatti C, Nojimoto T., Determination of malt and adjunct percentage in brazilian commercial beer through isotopic analysis. Ciênc.agrotec.2010; 34(1):163-172.

20. Venturini Filho, W G. Tecnologia de cerveja. Jaboticabal: FUNEP, 2000. 83p.

21.Kalnin J L et al. Avaliação estratégica para implantação de pequenas cervejarias. 124f. Tese (Doutorado em Engenharia de produção) - Centro Tecnológico da Universidade Federal de Santa Catarina, Florianópolis, 1999.

22. Hardwick W(Ed.). Handbook of brewing. New York: Marcel Dekker, 1995. 714p.

23. Haj-Isa N M A.. Estudo do uso de conservadores associados a tratamento térmico brando na preservação de cerveja a temperatura ambiente. 2000. $147 f$. Tese (Doutorado em Tecnologia de Alimentos) - Faculdade de Tecnologia de Alimentos, Universidade Estadual de Campinas, São Paulo. 2000.

24. Anderson, J. Malt: the essential flavour. 1. Confectionery Prod. 1995;61(3): 216218.

25. Garcia A I, Garcia L A, Díaz M. Fusel alcohols in beer fermentation process. Process Biochemistry.1994;29:303-309.

26. Bamforth C. W. Nutritional aspects of beer - a review. Nutr. Res. 2002;22:227237.

27. Siqueira, P B, Bolini, H M A, Macedo, G. O processo de fabricação da cerveja e seus efeitos na presença de polifenóis. Alimentos e Nutrição Araraquara.2009;19(4):491-498. 
28. Kondo K. Preventive effects of dietary beer on lifestyle-related diseases. EBC Proc.2003;1:133, 2003.

29. Arimoto K, S. et al. Inhibitory effects of heterocyclic amine-induced DNA adducts formation in mouse liver and lungs by beer. J. Agric. Food Chem.2005; 53:812-815.

30. Scalbert A, Williamson G., Dietary intake and bioavailability of polyphenols. J. Nutr.2000;130:2073S-2085S.

31. Lugasi A. Polyphenol content and antioxidant properties of beer. Acta Alim.2003;32(2):181-192.

32. Gerhauser C. Beer constituents as potential chemopreventive agents. Eur. J. Cancer.2005;41:1941-1954.

33. Kunze W. La cerveza terminada. In: KUNZE, W. Tecnología para cerveceros y malteros.VLB Berlin.2006; 7:826-885.

34. Valério, T B, Lima M T M A, Santos A F, Pereira P T V T, Câmara T A V, Consumo de bebidas alcoólicas na adiposidade corporal em estudantes universitários, Rev. Bras. de Obesidade, Nutrição e Emagrec.2016;10(60):263270.

35. Kachani, A T., Brasiliano S., Hochgraf P B., O impacto do consumo alcoólico no ganho de peso, Rev. Psiq. Clín.2008;35(supl 1):21-24.

4. Brix $=$ Medida informada pelo refratômetro, equipamento utilizado para medir a densidade da cerveja, que calcula o teor alcoólico.

Enviado: Dezembro, 2018.

Aprovado: Agosto, 2018. 